\title{
Exploring Buyer Motivation to Improve Management, Marketing, Sales, and Finance Practices in the Martial Arts Industry
}

\author{
Jason Earl Thomas ${ }^{1}$ \\ ${ }^{1}$ School of Business and Communication, Concordia University Texas and Coangelo College of Business, Grand \\ Canyon University, Phoenix, USA \\ Correspondence: Jason E. Thomas, School of Business Communication, Concordia University Texas and \\ Coangelo College of Business, Grand Canyon University, Phoenix, USA. Tel: 1-512-655-3038. E-mail: \\ jason.thomas@concordia.edu
}

Received: February 2, 2017 Accepted: February 22, $2017 \quad$ Online Published: March 2, 2017

doi:10.5539/ijms.v9n2p12 URL: http://doi.org/10.5539/ijms.v9n2p12

\begin{abstract}
The martial arts industry is experiencing immense growth, creating a highly competitive environment where challenges in attracting and retaining customers cause substantial losses and an inability to compete effectively. Customer memberships are the primary revenue source for fitness firms. Understanding buyer motivation is essential for marketing message creation and product development to attract and retain customers. The purpose of this qualitative, exploratory, single-case study was to investigate parent purchase motivation for children's martial arts classes and to document internal buying motives in order to address the problem of acquiring and retaining customers in the commercialized martial arts industry. The study sample consisted of seven parents, two instructors, and two owners. The data collection methods were semistructured interviews comprising open-ended questions. Interviews were analyzed using NVivo ${ }^{\circledR}$ qualitative analysis software to code and analyze themes. The semistructured interviews identified 10 themes. Three new themes emerged - ease of participation, alternative to team sports, and convenience. Study findings contribute to the theory of planned behavior and theories used to predict purchase behavior. Recommendations for practice include refinements of product offerings and marketing messages and the creation of a new market segment, resulting in customer alignment and increased ability to attract and retain customers. Future research is recommended to replicate this study in other geographies, to use the data gathered in this study to seed qualitative research studies, and to weigh the relative influence of the three types of behaviors influencing intention in the theory of planned behavior.
\end{abstract}

Keywords: buyer motivation, purchase behavior, consumer behavior, sports marketing, martial arts marketing, market segmentation, sales incentives

\section{Introduction}

Understanding the customer is a basic tenet of marketing theory and business success (Barbopoulos \& Johansson, 2016; Murphy \& Dweck, 2016; Yang, Stamatogiannakis, \& Chattopadhyay, 2015). Buyer motivation is the internal drive that causes people to identify needs and wants and to take action to fulfill those needs and wants by purchasing goods and services (Soloman, 2013; Yang et al., 2015). Marketers and researchers expend significant effort and resources attempting to understand consumer motivation, which is required to create sound business strategies and effective marketing messages (John \& Park, 2016; Murphy \& Dweck, 2016; Yang et al., 2015).

Maintaining awareness of buyer motivation is inherently difficult, as buyer motivation and consumer behavior are temporal and often change based on many variable social factors such as economic, social, and political trends (Baruk \& Iwanicka, 2016; Koenig-Lewis \& Palmer, 2008). Even though understanding buyer motivation is acknowledged as an important concept, acquiring and maintaining an understanding of buyer motivation is a significant challenge for business leaders because buyer motivation depends on several incentives simultaneously, such as achieving a goal, seeking pleasure, avoiding effort, affected perceptions, mindset, and avoiding pain (Barbopoulos \& Johansson, 2016; Murphy \& Dweck, 2016). Social trends are in a continual state of change. Technology, which underlies many marketing transactions, is also in a constant state of change. Consequently, customer motivations, expectations, and behaviors evolve with these changes, requiring periodic research for both theory and practice (Barbopoulos \& Johansson, 2016; Baruk \& Iwanicka, 2016; Yang et al., 
2015).

Current topics in consumer behavior research explore identifying internal motivations and their influence on behavior to predict outcomes (Murphy \& Dweck, 2016; Yang et al., 2015). The extant body of research indicates that goals held by consumers influence consumer behavior (Ajzen \& Klobas, 2013; Ajzen \& Sheikh, 2013), as well as individual self-construal (Wang, Ma, \& Li, 2015; White, Argo, \& Sengupta, 2012). Researchers have found that goals are subjective, vary by individual, and are connected to self-construal (Yang et al., 2015). Thus, marketers must seek to align factors like customer motivation and marketing messages such that, when connected, they can facilitate a sale or positive purchase decision.

Trends in the fitness industry are highly dynamic, requiring business owners to regularly assess the business environment and examine market demand (Mullin, Hardy, \& Sutton, 2013; Sobh \& Martin, 2012). The challenges of creating marketing messages and products that align with customer demand are exceptionally difficult in the commercialized martial arts industry, where a lack of historical interest in buyer motivation has left a gap in the body of knowledge regarding consumer behavior (Ko \& Yang, 2012; M. Kim, Zhang, Jackson, Connaughton, \& Kim, 2013; Rees, 2015). The rising popularity of martial arts has created growing consumer interest, new entrants into the market, and intensely increased competition for the industry-forcing business owners to develop more customer-centric business approaches (Greenwell, Hancock, Simmons, \& Thorn, 2015; Oh \& Lee, 2015; Reese, 2015).

\subsection{Background}

A key concern for many martial arts organizations is attracting and retaining clients (Kim, Zhang, Jackson et al., 2013; Ko, 2003; Ko \& Kim, 2010; Nelson, 2013). Addressing this concern requires obtaining an understanding of buyer motivation (Sobh \& Martin, 2012; Yang et al., 2015). The process of gathering data on customer motivation is iterative for marketers and businesses, requiring continual survey of market data and customer expectations (Barbopoulos \& Johansson, 2016; Yang et al., 2015). Understanding customer needs and knowing one's customer are essential elements of successful business planning. Knowledge of buyer motivation is used to develop products that meet market demand, craft appropriate marketing messages to attract and retain customers, create service offerings, and determine pricing methodologies (Baruk \& Iwanicka, 2016; Kim, Zhang, Jackson et al., 2013).

Even though understanding buyer motivation is acknowledged as an important concept, acquiring and maintaining an understanding of buyer motivation is a significant challenge for business leaders because buyer motivation depends on several incentives simultaneously, such as achieving a goal, seeking pleasure, avoiding effort, affecting perceptions, mindset, and avoiding pain (Barbopoulos \& Johansson, 2016; Murphy \& Dweck, 2016). The factors affecting consumer behavior and buyer motivation are temporal in nature and are constantly evolving (Koenig-Lewis \& Palmer, 2008; Soloman, 2013). Social trends are in a continual state of change. Technology, which underlies many marketing transactions, is also in a constant state of change. Consequently, customer motivations, expectations, and behaviors evolve with these changes, requiring periodic research for both theory and practice (Barbopoulos \& Johansson, 2016; Baruk \& Iwanicka, 2016; Yang et al., 2015).

The understanding and nature of theories regarding buyer motivation and consumer behavior have evolved over time (Barbopoulos \& Johansson, 2016; Yang et al., 2015). For example, early buyer motivation and consumer behavior theories focused on predicting buyer behavior based on the assumption that price is the sole motivator for purchases (Tverdohleb, 2012). Gradually, as the field of consumer behavior grew and matured, many theories evolved, considering both internal and external influences (Ajzen, 2014; Chen \& Tung; 2014; Kim, Zhang, Jackson et al., 2013; Shareef, Kumar, Kumar, \& Hasin, 2013). Examples of internal influences include roles, goals, lifestyle, and attitude, while examples of external influences include culture, group membership, and purchase situation (Galalae \& Voicu, 2013; Koter \& Keller, 2015; Petra, 2012).

Current trends in consumer behavior research revolve around identifying internal motivations and their influence on behavior to predict outcomes (Ajzen, 2014; Murphy \& Dweck, 2016; Yang et al., 2015). The extant body of research indicates that goals held by consumers often influence consumer behavior (Ajzen \& Klobas, 2013; Ajzen \& Sheikh, 2013; De Leeuw, Valois, Ajzen, \& Schmidt, 2015), as well as individual self-construal (Wang, Ma, \& Li, 2015; White, Argo, \& Sengupta, 2012). Researchers have found that goals are subjective, vary by individual, and are connected to self-construal (Yang et al., 2015). Accordingly, marketers must seek to align factors like customer motivation and marketing messages, such that when connected, they can facilitate a sale or positive purchase decision.

Advances in technology, communications, and growing customer expectations are rapidly evolving and affecting how consumers buy, evaluate, and perceive products and services. Firms, therefore, are required to assess their 
offerings and messaging continually in order to adapt to the evolving market demand (Baruk \& Iwanicka, 2016). Researchers have noted these trends and have identified internal buyer motivation as a key area for research to expand theories on buyer behavior prediction (Ajzen \& Klobas, 2013; Ajzen \& Sheikh, 2013; Wang et al., 2015; White et al., 2012).

The issue of consumer behavior is even more challenging in the martial arts industry. Historically, business owners have displayed a lack of interest in offering products to meet customer needs and wants, and only a limited body of consumer behavior knowledge exists in this area (Hall \& Ryan, 2013; Ko, 2003; Ko \& Kim, 2010; Reese, 2015; Wasik, 2014; Zeng, Cynarksi, Baatz, \& Park, 2015). The rising popularity of martial arts as a fully developed sport has created growing consumer interest, new entrants into the market, and intensely increased competition for the industry (Oh \& Lee, 2015; Ko \& Kim, 2010; Nelson, 2013; Reese, 2015).

\subsection{Statement of the Problem}

The problem addressed in this study was the acquisition and retention of customers for the commercialized martial arts industry. Customer acquisition and retention are the greatest challenges in the fitness industry (McKnight, Paugh, McKnight, Zuccaro, \& Tornabene, 2014; Williams, Pedersen, \& Walsh, 2012). Rapid growth has attracted large industry players to this market and has created intense market competition (Greenwell et al., 2015; Hall \& Ryan, 2013; Oh \& Lee, 2015; Nelson, 2013; Reese, 2015). Traditional martial arts firms struggle to understand customer needs and to adapt to new market conditions due to a lack of historical interest determining and meeting customer needs, limited research identifying customer purchase motivation, and an absence of tools to measure and identify market demand (Kim, Zhang, Jackson et al., 2013; Wasik, 2014; Zeng et al., 2015). Their struggle has resulted in a 41\% decrease in martial arts schools in the United States, from 14,500 in 2007 to 8,533 in 2015 (InfoUSA, 2015).

Children aged 6 to 12 represent approximately $60 \%$ of the customer base for the commercialized martial arts industry (Kim, Zhang, Jackson et al., 2013). Understanding buyer motivation is essential to creating effective marketing messages and appropriate product offerings (Kim, Zhang, Jackson et al., 2013; Ko \& Kim, 2010; Vinerean, Cetina, Dumitrescu, \& Tichindelean, 2013), which are necessary to attract and retain customers (Kim et al., 2013; Ko, 2003; Kim, Zhang, Jackson et al., 2013). Fitness organizations must regularly assess business environments and examine market demand to build and maintain business success (Baruk \& Iwanicka, 2016; Barbopoulos \& Johansson, 2016; Mullin et al., 2013). Accordingly, scholars have called for research regarding buyer motivation and internal motives influencing purchase decisions for the martial arts industry (Kim, Zhang, Jackson et al., 2013; Ko \& Kim, 2010; Nelson, 2013), as well as to expand and refine theories that explain buyer motivation and predict purchase behavior (Ajzen, 2014; Head \& Noar, 2014).

\subsection{Purpose of the Study}

The purpose of this qualitative, exploratory, single-case study was to investigate the buying motivations of parents who place their children in martial arts and to document internal buying motives to address the problem of acquiring and retaining customers in the commercialized martial arts industry. This information can be used to address the problems of acquiring and retaining customers in the commercialized martial arts industry by providing the data necessary to created effective marketing messages and appropriate market offerings (Oh \& Lee, 2015). Fitness organizations must regularly assess business environments and examine market demand to build and maintain business success due to highly evolving trends and market demand (Baruk \& Iwanicka, 2016; Barbopoulos \& Johansson, 2016; Mullin et al., 2013).

This study involved the utilization of a semistructured interview protocol to understand buyer motivation for parents who enroll their children in martial arts classes. Interview data were analyzed to identify the common themes that influence purchase decisions. The results from this study answer calls for research to examine internal motives and buyer motivation to expand and refine current theories that predict purchase behavior (Ajzen, 2014; Head \& Noar, 2014). Data derived from this study may be used to create new theories and theoretical models and to form a foundation for quantitative studies that further explore the topic (Cronin, 2014; Duxbury, 2012; Yin, 2014). Researchers studying the martial arts industry have called for research in this area to create marketing tools that assist in measuring market demand and identifying buyer motivation to generate appropriate marketing messages and strategies to attract and retain customers (Kim, Zhang, Jackson et al., 2013; Ko \& Kim, 2010; Nelson, 2013). Martial arts business owners could use this information to create effective value messages that are necessary to attract students and grow their business in competitive environments, which are essential components of business success (Oh \& Lee, 2015; Reese, 2015; Wasik, 2014). 


\subsection{Theoretical Framework}

Consumer behavior is a large area of study that is broadly discussed in peer-reviewed literature. The theory of planned behavior (TPB) was selected for the framework of this study because of its alignment with the purpose of this study and the ability to apply it to address the problem identified in this study. Further, the data derived by this study may be used to expand the theory by identifying motivations to be used as predictors of behavior, as requested by scholars who have called for additional research in this area (Shareef et al., 2013).

TPB is widely used in social science research to predict behavior (Klöckner, 2013). TPB stems from the theory of reasoned action (Fishbein \& Ajzen, 1975), which focuses on determining the effects of attitudes on behaviors. TPB evolved from the premise that individuals consider the implications of their actions prior to taking action (Webb \& Sheeran, 2006). Application of the theory of reasoned action assumes that individuals are in complete volitional control of some behaviors and are not in complete volitional control of other behaviors. The concept of differentiation of volition was the impetus to the development of the TPB variable, perceived control. TPB has two purposes: (a) predicting behavior and understanding motivational influences on the actions of individuals that may not be fully within an individual's control and (b) identifying opportunities to influence or change behavior (Figure 1) (Ajzen, 2006; Webb \& Sheeran, 2006).

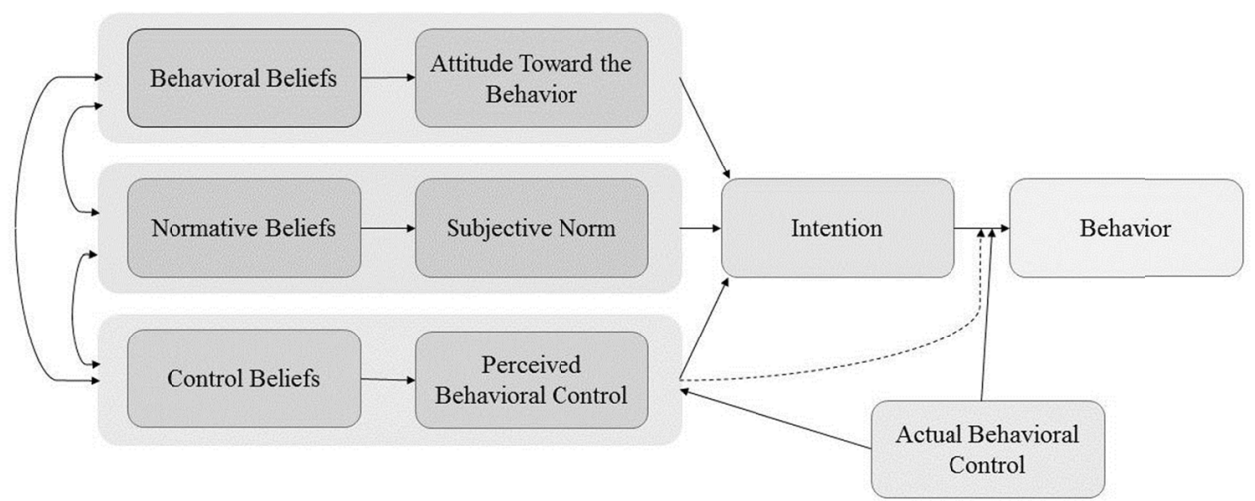

Figure 1. TPB model

Note. Adapted from “TPB Diagram” by Ajzen, 2006. Copyright 2006 by Icek Ajzen. (Permission granted for use for noncommercial purposes)

The application of TPB for questioning behaviors, such as parents placing their children in martial arts classes, requires one to assess the antecedent of the behavior - the individual's intention to perform the behavior (Ajzen \& Sheikh, 2013). Intentions are formed from three separate types of beliefs: (a) normative beliefs, (b) control beliefs, and (c) behavioral beliefs (Ajzen, 2013; Ajzen \& Klobas, 2013). Perceived control over performing behavior, attitudes, and subjective normative factors are latent predictor variables for these beliefs. Theoretically, they are antecedents of intentionality for performing behavior (Head \& Noar, 2014). Attitudes are the positive and negative viewpoints of an individual toward an action or object (Ajzen, 2006). Perceived control is one's own view of control versus the actual level of control possessed in performing a behavior.

\subsubsection{Examples of Using TPB to Examin Motivation to Predict Purchase Behavior}

TPB has been used explicitly in studies for the fields of marketing and business to better understand motivations and predict buying behavior. Kim et al. (2013) used TPB to understand customer engagement in buying from ecologically focused restaurants and to further understand consumer decision-making models. Subjective norm variables have the strongest predictive power for behavior, but attitudes toward behavior are the most easily influenced. Further, the researchers found that the predictive power of TPB could be improved by adding another variable - anticipated emotion (regret). Results indicated that internal drivers are strong predictors of buying behavior and that these drivers and perceptions can be easily influenced. Kim et al.'s (2013) research aligns exactly with the purpose of this study to examine the motivations of parents who place their children in martial arts classes and to address the problem of attracting and retaining customers. Kim et al.'s (2013) study is an example of how a study similar to this one can contribute to the refinement of TPB. The authors also proposed another internal variable for consideration in the TPB model, and the creator of TPB continues to call for the identification of addition internal motives to expand and refine the theory (Ajzen, 2014). 
Consumer adoption of the use of information and communication technology for purchases was examined through the lens of TPB in another study (Shareef et al., 2013). The underlying values for predicting behavior in TPB are valid for information and communication technology; however, other variables should be explored, such as perceived awareness and trust. Chen \& Tung (2014) conducted a somewhat similar study to extend TPB with a research model including environmental concern and perceived moral obligation to predict consumer use of green hotels. The researchers found that environmental concern is a valid influence on hotel selection (Chen \& Tung, 2014). Both of these studies show how research has been used to expand and refine TPB to enhance its effectiveness for predicting buyer behavior.

Use of TPB is common in the literature and is subject to vibrant discussion and debate. As scholars use and explore TPB, many have called for identifying additional internal drivers and motives in order to expand and refine the theory (Ajzen, 2014; Chen \& Tung; 2014; Gonzalez et al., 2012; Kim, Zhang, Jackson et al., 2013; Shareef et al., 2013). Critics of TPB have offered challenges in peer-reviewed articles, resulting in a debate of the merits and shortfalls of TPB and its use (Head \& Noar, 2014; Sniehotta, Presseau, \& Araújo-Soares, 2014). Ajzen's (2014) most recent defense of TPB was a response to Sniehotta et al. (2014). Sniehotta et al. (2014) asserted that TPB is not valid for predicting changing health-related behavior due the theory's static nature; however, Ajzen (2014) refuted the claim, suggesting that Sniehotta et al. (2014) did not fully understand TPB and had some misconceptions about its applications.

Most criticisms of TPB revolve around the concept that it is challenging to identify all of the internal variables that might be predictors of behavior and that applying TPB can be too complex for large studies with many subjects (Head \& Noar, 2014). While acknowledging the challenges of identifying appropriate predictors and the possibility of external interactions, Ajzen (2014) posited that there is no preclusion to adding new predictors, and with proper application and understanding the reliability of variables, the theory can be effectively used.

Therefore, TPB is an appropriate framework for this study for several reasons. The wide array of TPB use, expansion, criticism, and critical discussion indicates that TPB is a current and useful theory for research. Researchers have called for additional investigation to identify internal drivers and motivation to expand TPB (Ajzen, 2014; Chen \& Tung; 2014; Gonzalez et al., 2012; Kim, Zhang, Jackson et al., 2013; Shareef et al., 2013), which aligns with the purpose of this study. TPB has been used to effectively address problems similar to the one identified by this study (Chen \& Tung, 2014; Shareef et al., 2013). Moreover, the goal of this study was to examine the motivations of parents who place their children in martial arts classes, which aligns with the wide use of TPB to analyze internal motivations to predict behavior (Ajzen, 2014; Chen \& Tung; 2014; Gonzalez et al., 2012; Kim, Zhang, Jackson et al., 2013; Shareef et al., 2013). The use of TPB as a theoretical framework for this study was appropriate because the data derived were used to both expand TPB and to examine the problem of attracting and retaining customers for commercialized martial arts instruction.

\subsection{Research Question}

The research question was designed to explore the motivation of parents who place their children in martial arts classes. Subquestions were designed to facilitate meaningful interviews with study subjects. The following question was used as the central question for this study:

Q1. What motivates parents to purchase martial arts classes for their children aged 6 to 12 ?

\subsection{Literature Review}

Several areas of interest are included in the literature reviewed: purchase transaction roles, the introduction of martial arts to consumer and subsequent consumer adoption, martial arts marketing practices, and the specific martial arts outcomes. These areas of interest provide the foundation for understanding this research.

A gap in the literature was revealed in the area of buyer motivation for the commercialized martial arts industry. Identifying internal buyer motivations and measuring market demand are two great challenges in the commercialized martial arts industry, and there are few tools to assist with these tasks (Kim, Zhang, Jackson et al., 2013; Ko et al., 2010; Nelson, 2013). Data regarding buyer motivation are needed to address a serious business problem in the martial arts industry - attracting and retaining customers. Such attention is critical in order to adapt and thrive in an extremely competitive business environment by creating effective marketing messages and compelling product offerings (Kim, Zhang, Jackson et al., 2013; Ko et al., 2010; Nelson, 2013).

\subsubsection{Roles Used in Purchase Transactions}

Three roles exist in a typical purchase transaction: (a) payer, (b) purchaser, and (c) user (Sharma \& Kashimiri, 2012). The payer is the role assumed by the person who provides the funds for making a purchase, the purchaser is the role assumed by the person who physically makes the purchase transaction, and the user is the person who 
consumes or uses the product. Often a single person can fill all three roles. For example, it is common for an individual to order food, pay for food, and consume food from a fast-food restaurant. In this case, the individual has performed all three roles. However, another scenario could also occur in which a 5-year-old child asks her mother for a slice of pizza, the mother retrieves $\$ 5.00$ from her purse and hands it to the child's father, the father purchases the pizza, and the child consumes it. In this scenario, the mother is the payer, the father is the purchaser, and the child is the user.

While full discussion of family roles in purchasing is beyond the scope of this study, it is important to note that family dynamics create variables that can affect buyer motivation for parents who make purchases on behalf of their children. Purchases in the context of a family environment involve additional roles and nuances, such as decision-making style (Taghavi \& Seyedsalehi, 2015). Two varieties of decision-making styles are generally observed: the spouse-dominant decision-making style and the joint decision-making style. In the spouse-dominant decision-making style, one spouse is primarily responsible for purchase decisions, while in the joint decision-making style, both parents work together to make purchase decisions.

Several additional roles may manifest in a family purchase decision-making process, such as influencer and information gatherer (Taghayi \& Seyedsalehi, 2015). Influencers are members of the family that can influence outcomes. Both parents and children can perform this role. Children can exhibit behavior that influences purchase decisions. Children's attempts to influence purchases include systematically asking for something repeatedly, referred to as "pester power" (Powell, Langlands, \& Dodd, 2011, p. 97; Tghavi \& Seyedsalehi, 2015) Different pester power strategies are used based on a child's experience and level of maturity. Young children aged 3- to 4-years-old, who have not developed the cognitive skills to enable negotiation, use emotion-based methods of influence, such as screaming, frowning, temper tantrums, and other nonverbal methods. Older children employ more refined strategies, such as reminding the parent of recent good behavior as the reason they deserve to be given a certain product (Powell et al., 2011; Taghavi \& Seyedsalehi, 2015). Accordingly, while parents may execute the purchase process, parents' purchase decisions may be influenced to varying degrees by children and other members of the household.

\subsubsection{Martial Arts Industry Business Climate}

The martial arts industry has enjoyed increasing growth and participation since its introduction to the general public in the 1940s (Friman, 1998; Greenwell et al., 2015; Hall \& Ryan, 2013; Kim, Zhang, Jackson et al., 2013; Kim, Zhang et al., 2009; McNamara, 2008; Reese, 2015). In 2005, eight million Americans were reported to practice traditional martial arts (Zetaruk, Violan, Zurakowski, \& Micheli, 2005), and by 2015, there were an estimated 8,533 martial arts schools in the United States (InfoUSA, 2015). Furthermore, as of 2011, the martial arts industry was estimated at $\$ 50$ billion and climbing (Green, 2011).

Martial arts students receive instruction in for-profit martial arts schools, nonprofit clubs, fitness programs, public health programs, programs at institutions of education, and military programs (Kim, Zhang, Jackson et al., 2013). According to Ko \& Kim (2010), "Today, martial arts have become an integral part of sports and physical activity culture that convey lifestyles and values of education and entertainment" (p. 105). In essence, martial arts have become part of mainstream culture and are a generally accepted physical activity like football, soccer, gymnastics, or dance. Children are as familiar with martial arts characters, like Teenage Mutant Ninja Turtles and Kung Fu Panda, as they are with other characters marketed toward children, like Mickey Mouse.

Robust growth of martial arts participants, products, and organizations has caused martial arts to become global cultural products (Cynarski, 2013; Ko \& Yang, 2012). This globalization is attributed to five factors: (a) the transformation of values of martial arts to include entertainment, (b) the modernization of martial arts school curriculum, (c) efforts by governments of the martial-arts-originating countries, (d) expansion of martial arts in the market as they evolved into sports, and (e) the diversification of martial arts products beyond traditional instruction, such as movies, fitness programs, and professional competitions (Ko \& Yang, 2012). This has resulted in expanded business opportunities and new challenges, such as increased competition (Kim, Zhang, Jackson et al., 2013; Ko \& Kim, 2010; Ko \& Yang, 2012).

\subsubsection{Martial Arts Industry Consumer Behavior Research}

A fair amount of research exists regarding the exploration of the benefits and outcomes of martial arts training (Ding, Chen, Zou, \& Tian, 2015; Kim et al., 2009; Vertonghen \& Theeboom, 2013; Zou, Zhang, \& Ouyang, 2014). Research on consumer behavior and buyer motivation in the martial arts industry, however, is limited and does not address marketing concepts, such as motivation for participation or market demand (Ko \& Kim, 2010; Kim, Zhang, Jackson et al., 2013; Nelson, 2013). The lack of information regarding buyer motivation and consumer behavior in the martial arts industry can be attributed to the unique evolution of the martial arts 
industry, which, early in its history, restricted its exposure to the public (Ko \& Yang, 2012; Kim, Zhang, Jackson et al., 2013).

Martial arts business practices have historically been atypical. For several decades, business owners had little interest in understanding buyer motivation or even offering services to the general public (Kim, Nijite et al., 2013; Kim, Zhang, Jackson et al., 2013; Ko \& Yang, 2012; Nelson, 2013). Martial arts school owners restricted the number of students and often did not advertise at all (Choi, 1965; Kimm, 2014; Ko \& Yang, 2012). Instructors desired to push a certain a product rather than answer the needs and wants of customers. Further, public knowledge of martial arts was limited (Ding et al., 2015; Vail, 2014); views on what martial arts are and their benefits ranged from gaining mystical abilities to fighting skills and mundane fitness (Jones et al., 2006; Kimm, 2014; Vertonghen \& Theeboom, 2013).

This complicated nature of the martial arts business evolution and the mired public view and understanding of martial arts make market demand difficult to assess. Kim \& Zhang et al. (2009) noted the lack of tools to assess market demand and conducted a study to build a tool to assess market demand; however, the tool does not appear to be broadly accepted. Four years later, Kim, Zhang, \& Jackson et al. (2013) reexamined the tool and found that the previous research team had inserted a factor about appreciation for Asian culture that was recognized to be an irrelevant factor in demand. This error was likely based on preconceived notions of demand for traditional martial arts being based on a desire to participate in ancient Asian culture. For these reasons, it is important to review the history of the martial arts industry, its evolution, and how consumers perceive the industry.

\subsubsection{Introduction of Asian Martial Arts to United States Consumers}

Initially, martial arts business owners were secretive about instruction; the public knew very little about how martial arts schools operated and even less about what martial arts were (Choi, 1965, Kimm, 2014; Ko \& Yang, 2012). The veil of secrecy colored public perception about martial arts and affected buyer motivation and product adoption. Interest in martial arts was bolstered by the United States military and, as a result, martial arts popularity in the United States grew rapidly at the end of World War II (Friman, 1998). In the 1940s, prominent military officers started encouraging training and invited instructors to teach American servicemen at installations overseas. By the 1960s, formally trained American instructors joined their foreign counterparts, creating a broader foundation for teaching martial arts to Americans (Friman, 1998).

Even though the United States gained a larger capacity for training students in martial arts, the concept of martial arts did not spread broadly to the general public. Hong Kong action movies portrayed martial arts as early as 1920 and began to make an impact in the American movie and television market in the 1960s (Asay, 2009). The generic Hong Kong Kung Fu movies were quickly followed by action film superstar Bruce Lee in the 1970s, who began to appear in exciting major motion pictures with large studio support that addressed current social issues, such as the Vietnam conflict (Asay, 2009). Audiences were mesmerized, and Bruce Lee became a household name. These stimuli created some initial public perceptions of martial arts and created the initial buyer motivation for martial arts lessons. Essentially, customers wanted to learn ancient and secret martial arts skills to gain new and extraordinary abilities (Ding et al., 2015). Interestingly, while this was a factor in creating buyer motivation for some, the same perception was a negative motivator for others who perceived these skills as generally unattainable by Westerners (Asay, 2009; Green \& Svinth, 2003).

Bruce Lee's popularity captured a real mindshare for the American public and introduced martial arts to the masses (Asay, 2009; Ding et al., 2015; Locke, 2014). Prior to Bruce Lee's rise to stardom, martial arts theater appealed to a small niche market; afterward, martial arts became more mainstream (Ding et al., 2015). Bruce Lee's impact on American culture was so strong that Locke (2014) asserted that the main character's alter ego in David Fincher's Fight Club was a twin metaphorical Bruce Lee, creating an equivalent icon for the "white man" (p. 80).

Bruce Lee's cinematic accomplishments were followed by two decades of martial arts movies that continued to saturate the American public with martial arts characters and concepts. In the 1980s, a new wave of big screen entertainment continued exposure to American movie audiences with blockbuster movies such as The Karate Kid and the cult classic Blood Sport, as well as the popular ninja craze. Audiences became familiar with stars who would become household names, such as Jackie Chan, Chuck Norris, and Jet Li, and their associated martial arts styles (Ding et al., 2015; Nelson, 2013; Vail, 2014). This additional exposure generated increased interest in the martial arts. More importantly, films like The Karate Kid projected an image of the martial arts as accessible to everyone; an average person could take classes and train diligently to gain extraordinary abilities. Consequently, enrollment in martial arts classes grew (Asay, 2009; Green \& Svinth, 2003; McNamara, 2008).

The next stage of development that bolstered consumer exposure to martial arts was the evolution of martial arts 
as a participatory sport. Local tournaments were hosted as mechanisms for students to practice and test their skills in competition. This led to national competitions and, eventually, the development of martial arts such as judo, wushu, and taekwondo as Olympic sports (Kim, Zhang, Jackson et al., 2013; Ko \& Kim, 2010; Nelson, 2013). This evolution not only provided more exposure for martial arts, but also provided an outlet for martial arts practitioners to have extended aspirations of becoming Olympic athletes.

The latest stage of development in the martial arts, the evolution of mixed martial arts (MMA), dramatically changed the face of martial arts practice and consumerism (Naraine \& Dixon, 2013; Nelson, 2013; Wells, 2015). As its name implies, MMA includes elements from multiple martial arts. MMA has provided a robust area of professional-level competitions similar to other sports such as baseball. Fans can now watch planned events and root for their favorite fighters. MMA is a mainstream sport with televised matches, USA Today weekly coverage, sports talk radio shows, and coverage by ESPN (Wells, 2015). MMA matches are even sanctioned by government entities in a similar manner to professional boxing events (Naraine, \& Dixon, 2013). The success of the MMA segment alone is a strong indicator of its popularity among consumers. The Ultimate Fighting Championship, a single MMA organization, generates \$250 million in annual revenue and has an estimated worth of more than $\$ 1$ billion (Miller, 2008). The martial arts industry has become a substantial business, as well as a part of American popular culture.

\subsubsection{Martial Arts Marketing}

Children represent $60 \%$ of the student base for traditional martial arts businesses and are the largest customer segment. While there is a plethora of information in popular media about the benefits of martial arts, researchers examining such benefits for martial arts participation have yielded mixed findings, ranging from general social benefits to negative outcomes, such as enhanced aggression (Ball \& Martin, 2012, Cynarski, 2013; Vertongen \& Theeboom, 2010; Zeng et al., 2015).

A foundational concept in marketing is to develop a succinct understanding of customer needs and their motivations for buying (John \& Park, 2016; Yang et al., 2015). Dividing customers into groups to better understand their needs and buying patterns is known as "market segmentation" or "segmenting" (Soloman, 2013; Vinerean et al., 2013). Market segmentation and tailoring business offerings to the needs and wants of the customer has traditionally been of little interest to martial arts school owners (Ko, 2003; Ko \& Yang, 2012; Nelson, 2013).

Historically, martial arts instructors have been more concerned with distributing their personal philosophy, transmitting information as taught to them, and preserving their art and way of traditional teaching rather than adapting to meet customer needs; therefore, it has not been uncommon for schools to screen students or use exclusionary practices. Nevertheless, rapid growth and product development in the martial arts industry has led to increased market demand (Hall \& Ryan, 2013; Reese, 2015). The growth has created greater opportunities and stronger levels of competition (Nelson, 2013; Oh \& Lee, 2015). The combination of increased market demand and enhanced business opportunity has created a "buyer's market", as many businesses are seeking to satisfy the market demand and create thriving businesses. Consequently, the success of a martial arts business has come to depend on a firm's willingness to adapt and meet consumer needs and wants (Ko et al., 2010; Nelson, 2013; Oh $\&$ Lee, 2015).

Even though martial arts school owners may have begun to embrace the concept of adapting to customer needs, there is a lack of information on customer motivation for participation in martial arts classes (Cynarski, 2013; Ko \& Yang, 2012; Vinerean et al., 2013). Without the knowledge of buyer motivation to purchase and participate in classes, information on how to satisfy customer needs and wants remains incomplete, making it difficult for business owners to construct appropriate marketing messages to attract and retain customers, develop target market strategies, and facilitate business growth.

\subsubsection{Motivation for Participation}

Although the present popular opinion of martial arts is focused on self-defense and fighting prowess, the limited amount of recent research on adult motivation shows that the leading motive for pursuing training is physical fitness improvement (Vences de Brito, Rodrigues, Cynarski, \& García, 2015; Witkowski, Cynarski, \& Blazejewski, 2013). Cynarski (2012) indicated that the motivational factors for participation of young people are both unconscious and conscious. Conscious factors identified by Cynarski (2012) are physical fitness, acquiring fighting skills, gaining a sense of confidence or security, social interaction, and competition. Unconscious factors are influences of hero-like role models, personal needs for security, group acceptance in the local martial arts group or broader martial arts community, and proof of training accomplishment. However, Cynarski's (2012) assertions were based on a brief literature review of outcomes and personal experience rather than direct research 
and interviews. Zeng et al. (2015) found the motivational factors for participating in taekwondo competitions to be physical fitness, enjoyment, self-defense, and education.

Other studies in this area have been focused narrowly through either examination of specific martial arts (Kim, Zhang et al., 2009) or in specific population groups (Jones et al., 2006). Kim \& Zhang et al. (2009) asserted that the reason for the dearth of studies examining martial arts motivation is the lack of a proper measurement tool for market demand. The authors created the SDM-Taekwondo to address this issue for taekwondo businesses, as taekwondo is a prominent and commercially viable martial arts style with an estimated 70 million participants; however, the tool has yet to be tested (Kim, Zhang, Jackson et al., 2013).

\subsubsection{Summary}

Many of the motivators for marital arts participation have been identified as being similar to other sports (physical fitness, fun, skill development, camaraderie) (Jones et al., 2006). Unique elements of martial arts, such as philosophy and the mind-body-spirit approach, were not examined by Jones et al. (2006), but other scholars have found these items to be significant as motivation for participation (Iedwab \& Standefer, 2000). While refining the SDM-Taekwondo, Kim, \& Zhang et al. (2009) were surprised to find that cultural learning is not a significant factor in market demand. Later, when seeking to revise the SDM-Taekwondo, Kim, Zhang, Jackson et al. (2013) found that cultural learning is a significant factor in market demand. This inconsistency in the body of knowledge, even by teams led by the same researcher, leads to questions about the maturity level and sufficient quantity of research within the body of knowledge in this area.

The majority of studies centered on motivation seem to have focused on adult student participation (Kim, Zhang, Jackson et al., 2013; Ko \& Kim, 2010). This indicates a gap in the literature for studying the motivation of children who participate in martial arts classes. Kim \& Zhang et al. (2009) stated that the majority of taekwondo students are children under the age of 18. Tibor Siklosi, the Director of Innovation for Century Martial Arts, stated that Century Research Group shows that over 60\% of martial arts students are under the age of 13 (Siklosi, personal communication, June 3, 2016). Kim, Zhang, Jackson et al. (2013) cited potential market growth for the smaller customer segment - adults - as a reason to focus on adults for study. While this logic may be valid, one can explore many alternative reasons beyond an underserved market for the large density of children as students, such as the physical requirements for participation in the sport, the amount of time needed to dedicate to the sport, or the available amount of free time for such activities. Adults may simply not have as much time to participate. Additionally, population size of the market segment is not the sole indicator of growth potential (Soloman, 2013).

Market saturation must also be considered. Zetaruk, Violan, Zurakowski, \& Micheli (2005) estimated the population of martial arts participants at eight million. The United States Census Bureau (2015) estimated the United States population at 316,128,839. This represents a market saturation of approximately one-quarter of $1 \%$. Clearly, there is room for substantial business growth for the martial arts industry for instructing all age demographics.

Studies with children may be difficult to implement due to literacy issues (Theeboom et al., 2009). Theeboom et al. (2009) conducted a study examining children's motivation and found that items such as self-defense, specific activities, and fitness are important motivations for children in classes. However, these data may not create a complete picture for martial arts marketers, as children do not always have the buying authority in purchasing decisions (East et al., 2013; Hoyer et al., 2012).

The process of buying is complex, and three distinct roles occur in any purchase: (a) user, (b) buyer, and (c) payer (Sharma \& Kashmiri, 2012). Whereas adults may often act in all three of these roles simultaneously (East et al., 2013; Hoyer et al., 2012), children, especially younger ones, often act simply as the user of goods and services (East et al., 2013; Hoyer et al., 2012). The buyer and purchaser roles are more likely held by the parents of a child (East et al., 2013; Hoyer et al., 2012).

Researchers have observed that rapid growth in the martial arts industry has created a number of complex changes in the business environment, including increased competitiveness, changes in the balance of market supply and demand, evolving customer needs and wants, and dynamic market demands for new products and services (Nelson, 2013, Oh \& Lee, 2015; Reese 2015; Zeng et al., 2015). In the past, traditional martial arts instructors have been unwilling to adapt to customer needs and wants and have been reticent or unwilling to change their product offerings (Ko, 2003). Increased market competition and the evolution of consumer choice make it necessary for business owners to adapt to customer needs and wants (Kim, Zhang, Jackson et al., 2013; Ko \& Kim, 2010; Nelson, 2013). 
The customer segment from which a business can earn the most revenue is called the primary target market segment (East et al., 2013; Soloman, 2013). Understanding the motivation of the buyers for the primary target segment is necessary for growing business and attracting new students (Soloman, 2013) and is of paramount importance in the martial arts industry, as customer acquisition and retention are the greatest challenges in the sports and fitness industries (McKnight et al., 2014; Williams et al., 2012). This appears to be a large gap in the current body of peer-reviewed literature for the martial arts industry, and scholars have called for more research in this area (Kim, Zhang, Jackson et al., 2013; Ko \& Kim, 2010; Nelson, 2013).

The literature has exposed a need to gather critical business data to enable the creation of market strategies and marketing messages (Kim, Zhang, Jackson et al., 2013; Ko \& Kim, 2010; Nelson, 2013; Vinerean et al., 2013). Failure to understand the motivations of customers prevents business success and growth by hindering the ability to develop effective marketing messages and strategies (Baruk \& Iwanicka, 2016; Barbopoulos \& Johansson, 2016; Mullin et al., 2013). Scholars have identified this need and have begun efforts to gather information about participation motivation for several market segments. These segments include adult taekwondo students, martial arts students who attend competitive tournaments, MMA students in Korea, and child participants in the role of users of martial arts lessons (Kim, Zhang, Jackson et al., 2013; Ko \& Kim, 2010; Nelson, 2013; Twemlow et al., 2008).

Many areas remain unexplored. Arguably, the most significant market segment remains unexamined-the primary target market segment for taekwondo - children aged 6 to 12 (Kim, Zhang, Jackson et al., 2013; Ko \& Kim, 2010). Further, the literature has revealed several key perceived benefits, such as bullying prevention and addressing obesity, which could be used as propositions to help frame exploratory research for this segment (Kim, Zhang, Jackson et al., 2013; Ko \& Kim, 2010; Nelson, 2013).

\section{Research Method and Design}

This study was a qualitative, exploratory, single-case study grounded in an inductive strategy. The goal of this research was to answer a how or why question. Qualitative case studies are best used to answer how and why questions (Tetnowski, 2015; Yin, 2014). Quantitative methods, such as surveys, are better at answering who, what, how many, where, and how much questions, but are less effective at answering how or why questions (Baškarada, 2014). Furthermore, qualitative research methods provide the opportunity to gather thick, in-depth, rich data (Cronin, 2014; Dasgupta, 2015). Case study research is a useful method to expand theories by combining current theoretical knowledge with new insights gained from empirical data (Cronin, 2014; Duxbury, 2012; Yin, 2014). Case study research is especially useful in situations where little is known about howor why events, actions, and behaviors occur in real-life situations, as well as where current perspectives appear inadequate (Baškarada, 2014; Dasgupta, 2015; Denham \& Onwegbuzie, 2013; Tetnowski 2015; Yin, 2014).

This study was an examination of business that has little consumer behavior research associated with it and is currently transforming into a robust and mature business segment (Kim, Zhang, Jackson et al., 2013; Ko \& Yang, 2012; Nelson, 2013). Accordingly, there is not a strong foundation of research from which to draw data and little market data to use to construct tools such as surveys for quantitative studies. Scholars have identified the need for empirical data regarding the motivations of buyers in the martial arts industry for both practice and research (Kim, Zhang, Jackson et al., 2013; Ko \& Kim, 2010; Nelson, 2013). Likewise, scholars have called for additional research on internal motivations that can be used to expand theories that predict behavior (Ajzen, 2014; Head \& Noar, 2014). One of the main value propositions of this research is that it will establish a pool of data that can be used to seed quantitative studies (Cronin, 2014). Moreover, qualitative methods are used to examine specific aspects of consumer behavior to probe below the surface and explore drivers and motivations of consumers, which creates a starting point for understanding consumer behavior (Dagupta, 2015; Sharma \& Kashimiri, 2012).

Yin's (2014) techniques for conducting case study research were followed. These techniques include (a) generation of the problem statement, (b) creation of research questions, (c) establishment of case study design and approach, (d) preparation for data collection, (e) collection of data, (f) analysis and evaluation of data, and (g) reporting of case study findings. Because this study was grounded in why questions in an attempt to understand the cause for behavior of a specific contemporary phenomenon, case study was deemed the most appropriate design (Dasgupta, 2015; Tetnowski 2015; Yin, 2014).

Data were collected in a purposeful manner (Robinson, 2014) using semistructured interviews. Multiple data collection methods and interviews were conducted with three types of stakeholders - parents, instructors, and owners - to achieve triangulation of sources and diverse points of view (Houghton et al., 2013; Mertens \& Hesse-Biber, 2012). The strategy for participant selection was criterion sampling with homogenous participants 
(Robinson, 2014) to yield information-rich results (Cronin, 2014; Dasgupta, 2015; Yin, 2014).

\subsection{Population}

The target population for this study was the parents of students aged 6 to 12 taking martial arts lessons at a school in Lakeway, Texas, the instructors who teach the children and interact with parents, and the owners responsible for marketing and sales strategy and teaching classes. The specific characteristics of the population included being the buyers who make the purchasing decisions and the actors who interact with the buyers to facilitate sales and create product offerings and marketing messages. The total population was estimated to be the parents of 30 students aged 6 to 12, three instructors, and two owners. The population was appropriate for this single-case study because the purpose of this qualitative, exploratory, single-case study was to investigate the buying motivations of parents who place their children in martial arts classes and to document internal buying motives to address the problem of acquiring and retaining customers in the commercialized martial arts industry.

\subsection{Sample}

Sampling in qualitative research is influenced by both practical and theoretical factors (Robinson, 2014). This study involved the employment of a criterion sample strategy. Criterion sampling and purposeful data collection are synonymous with qualitative research (Robinson, 2014). Therefore, it was pivotal to identify participants with actual experience with the phenomenon under study to obtain in-depth insight (Marshall, Cardon, Poddar, \& Fontenot, 2013). The criterion for selecting parents of children aged 6 to 12 was that this group represents the primary target market segment for taekwondo schools (Kim, Zhang, Jackson et al., 2013; Ko et al., 2010). The criterion for selecting owners and instructors was that these individuals interact with parents during presales and purchase activities and service delivery, and they create the marketing messages to attract parents as customers. All study participants conformed to these criteria of being a parent of a child aged 6 to 12 taking lessons, being an instructor, or being an owner.

In quantitative studies, sampling logic is a common factor of study design; however, sample sizes are usually irrelevant in qualitative, single-case studies (Baxter \& Jack, 2008; Robinson, 2014; Yin, 2014). Some researchers suggest that 10 or fewer study participants are required to obtain thematic saturation for qualitative studies (Mason, 2010; Robinson 2014), while others recommend 10 to 15 interviewees (Houghton, et al., 2013; Marshall et al., 2013). Generally, researchers strive to achieve data saturation, when collecting data no longer yields new motives, insights, themes, or information (Houghton et al., 2013; Suri, 2011). As there is a wide range of views on an appropriate sample size for qualitative studies, this research focused on saturation, and a sufficient number of interviews were conducted to achieve thematic saturation, when three of the last five interviews yield no new data or themes (Mason, 2010; Robinson, 2014). The sample pool of seven parents, two instructors, and two owners provided ample opportunity to achieve saturation. Study participants were recruited by email introduction letters.

\subsection{Materials/Instruments}

The instrument used for this study was a case study protocol. Case study protocol creates reliable research and guides the researcher through the process of data collection (Yin, 2014). The method of data collection in this single-case study was semistructured interviews. Semistructured interviews allow for focused sessions in which the researcher has identified a specific topic, developed a limited number of questions, and prepared a list of follow-up questions (Rubin \& Rubin, 2012).

Semistructured interviews were conducted with the parents, instructors, and owners. The interviewer used open-ended questions that were developed based on an extensive review of the literature and incorporated into an interview guide. The guide contained the list of questions and subject areas to be explored in the interview and was used as a basis to build conversations. This allowed for consistency in interviews, but still allowed interviews to be fluid and increased the ability to obtain in-depth information. The interview guide helped facilitate timely and efficient interviews (Rubin \& Rubin, 2012; Yin, 2014).

Semistructured interviews have been used to guide interviews rather than control them and to develop coding schemes (Yin, 2014). Semistructured interviews are commonly used in business and consumer behavior studies (Al-Fattal \& Ayoubi, 2012; Bjerke \& Ind, 2015). Al-Fattal \& Ayoubi (2012) used semistructured interviews to explore buyer motivation for foreign language training. Bjerke \& Ind (2015) used semistructured interviews to explore motivation around corporate art purchases.

A field test was used to validate and refine the interview questions and interview guide (Baxter \& Jack, 2008). To review the interview questions, a small group of respondents was used with similar backgrounds to those 
targeted for the formal case study. Respondents were asked to comment on the wording, language, and interpretation of the interview questions, with their responses considered for revision.

Interviews were conducted in a natural setting at the martial arts school or over the phone, if necessary. In-person interviews were preferred because of the opportunity for nonverbal communication and direct observation (Yin, 2014). All interviews except one were audio-recorded. An interview guide was used to conduct interviews, and participants were asked about their choices and influences, as well as perceived value propositions. Research was conducted over 5 weeks.

Participants were asked open-ended questions about the reasons for putting their children in a martial arts class. Several themes were explored with participants, such as motivation for selecting martial arts, key influences, perceived benefits, and needs being met by martial arts classes. Interviews were closed, with debriefing that included asking for any additional questions or comments from the respondent, a review of the data gathered from the interview, an explanation of the next steps for analysis and data collection, a request to follow-up later for a brief member check by call or email, and a final thank you for taking the time to participate.

\subsection{Data Collection, Processing, and Analysis}

The method for gathering data consisted of three phases. First, informed consent was obtained by means of a signed informed consent form. Qualitative semistructured interviews were conducted with parents of children in martial arts classes, instructors, and owners. Interviewing these three groups of stakeholders helped the study achieve triangulation of sources by providing three different perspectives on this phenomenon Baxter \& Jack, 2008; Bekhet \& Zauszniewski, 2012). Semistructured interviews are used in qualitative research when the researcher is attempting to collect facts (Walker, 2012). Interviews were transcribed and then analyzed in accordance with Leedy \& Ormrod's (2015) suggested approach of defining the concept and relationships, converting text to frequency distributions, examining contexts of frequency distributions and relationships within contexts, and displaying the resulting maps graphically. NVivo ${ }^{\circledR} 11$ Pro for Windows ${ }^{\circledR}$ software was used for content analysis to provide insight into the data and assist with coding and content factor analysis. The questions and framework for interviews were vetted by other experienced qualitative researchers from the dissertation committee and institutional review board (IRB) to ensure validity of the study methodology and approach.

Member checking is the process of verifying data, interpretations, analytic categories, and conclusions with study participants to verify that their statements were accurately captured and to ensure the validity of the study (Mertens \& Hesse-Biber, 2012; Reay, 2014; Reilly, 2013). Shortly after the initial data were gathered, transcribed, and coded, formal member checks were conducted by means of telephone calls and/or emails to confirm responses, ensure that data were captured accurately, and inquire for any additional reflections on the topic since the initial interaction. Lincoln \& Guba (1985) described member checks as essential for establishing credibility in qualitative studies. After data were refined and validated based on the member checks, credibility was further established by using quotations that captured participant responses objectively, exactly as stated during the interview process, demonstrating researcher neutrality (Bekhet \& Zausniewski, 2012). The robust and focused approach ensured that data captured about the phenomenon were accurate reflections of the study participants and were valid, reliable, and meaningful for the study purpose.

\section{Results}

Participant responses were reviewed to create a list of notable and meaningful statements that were analyzed for patterns and then coded into themes. All data were de-identified, and no names were used during data collection or analysis. Parent interviewees were designated by the pseudonym PI-XX, instructors were designated as I-XX, and owner-instructors were designated as OI-XX, where XX represents a two-digit coded nonsequential number to preserve anonymity.

\section{Themes from Interviews}

Themes were overarching in nature and were referred to multiple times by multiple participants in response to multiple subquestions (Sargeant, 2012) and are presented in Table 1. 
Table 1. Themes and interview groups

\begin{tabular}{llll}
\hline Themes & \multicolumn{2}{l}{ Interview Group } & \\
& Parents & Instructors & Owner/Instructors \\
\hline Self-defense & $\mathrm{X}$ & $\mathrm{X}$ & $\mathrm{X}$ \\
Physical fitness & $\mathrm{X}$ & & \\
Ease of participation & $\mathrm{X}$ & $\mathrm{X}$ \\
Alternative to team sports & $\mathrm{X}$ & \\
Discipline & $\mathrm{X}$ & \\
Free trial class & $\mathrm{X}$ & & \\
Affordability & $\mathrm{X}$ & $\mathrm{X}$ \\
Media influence & & $\mathrm{X}$ & $\mathrm{X}$ \\
Bullying & & $\mathrm{X}$ & \\
Convenience & & $\mathrm{X}$ & \\
\hline $\mathrm{N}=10$ & & & \\
\hline
\end{tabular}

Theme 1: Self-defense. Several parents stressed that learning to cope with confrontation appropriately (e.g., not always with violence) was a value they hoped to receive from martial arts training. PI-38 stated, "I also think it's good to know how to protect yourself if you were to get into a bad pinch". PI-38 further elaborated:

Boys are boys on the playground and maybe what he learns here could be productive in terms of - not that he's going to turn around and do a taekwondo kick on somebody - but maybe just in terms of also what they teach about being calm, being reactionary, not overreacting, could come in handy, just also building their personality and how they work through conflict.

PI-43 stated, "We were looking for [child] not only to defend himself, but also build some self-confidence, and the respect from junior to senior is very, very important". PI-91 identified developing poise under fire as a benefit: "I like the fact that they would feel confident enough to take steps to protect themselves, and that was certainly a motivation in coming and continuing to come to class". PI-29 relayed a tangible self-defense example:

...one example is, my daughter was thrown down at school. Kind of like punched down by a kid, jumped into a guard, and she was kicked and hit in the stomach and hit in the head all that time and she just ... she guarded herself well.

Theme 2: Physical fitness. PI-99 and PI-82 mentioned flexibility as a valuable fitness gain. PI-82 stated, “...one thing that I think martial arts does, this particular one anyway, that we were missing - my boys were missing in their other activities - was flexibility".

Other parents provided quick comments about fitness as a motivation. PI-29 said, "Just knowing that it's better for kids, that exercise is, especially psychologically". Similarly, PI-91 added, "General fitness influenced it..." Other parents felt that martial arts were a worthy addition to help maintain fitness. PI-91 reflected, "They were in excellent shape, and we wanted to make sure that that stayed the same". PI-43 found martial arts to be a good component of an overall fitness program and reflected, "Also, I like the physical aspect of it".

Instructors and owner/instructors also emphasized physical fitness as a motivation. I-33 said, "I'd say from my experience and in the thing it could be to keep the child active. In some cases, my experience is children that have asthma, being a particular illness, join taekwondo and it's helped with that". I-66 added, "...as for the fitness, some kids, they just need to move around again. The bear crawl, burpees, it's good for their development physically".

OI-18 said, "In terms of fitness, absolutely. As schools continue to cut back on recreational time, gym time, that's a large factor". OI-05 added, "Well, they want to get their children stronger, physically stronger and be more focused".

Theme 3: Ease of participation. Parents expressed that keeping up with children's extracurricular activities was challenging. PI-82 expressed challenges with management schedules for a larger family:

I would say that with five kids, I've tried just about every extracurricular activity, trying to find things that suit my kids and that they enjoy. It needs to be nearby. It needs to be affordable. It needs to fit with the schedules of all the other people in the family ... it was near the other kids' activities and it was the right time of day, right days of the week.

Key motivators were the availability and convenience of classes as compared to other activities. 
PI-91 commented, "Yeah... the flexibility of the time schedule, the different time slots. Timing here wasn't a burden to them as swimming was". Other parents appreciated the business model design, which made it easier for children to attend classes. According to PI-29, "Honestly, it was the after-school program. The after-school program, and it was a good deal". PI-12 validated PI-29's thoughts, stating, "School pick-up makes it easier. Time-wise efficient, affordable, and a complete package. Easily doable for parents in a working environment".

Theme 4: Alternative to team sports. Some parents felt that their children were better suited to individual activities. Owner/instructors also identified this as a strong purchase motivator. PI-38 shared, "I think it's also that not every kid is built for a team sport. This is something individually that they can work and strive for in the pursuit of a belt color to the next belt color to the next". Likewise, PI-82 said, "I'd say just probably getting fatigued with team sports. Some people are team-sport people and some people are individual-sport people".

Other parents were looking to get away from the negative aspects of competitive team sports. The following is according to PI-91:

Okay, we come from a competitive team-sport background, both my husband and I, and all of the activities prior to this one for both of my children. In making this decision, I wanted away from that. We had been there. We had done that. We gained the lessons that were appropriate, and coming to martial arts was an opportunity for them to participate in something where you got out of it as much as you put into it, the athlete themselves, so whenever my children show up, however hard they're willing to work, that's what they'll get out of it. It is not dependent upon someone else.

Similarly, PI-82 felt, "They [children] liked that [taekwondo] a lot more, they found that it was more rewarding and less pressure than keeping up with a team". PI-12's child refused to participate in team sports. When the child was enrolled in baseball, he did not enjoy the sport and was not motived to participate. During a game, he walked up to the coach and said he was done with the sport. PI-82 concluded the following:

...we started with team sports, and they felt a lot of pressure in the team environment, so things like baseball or even flag football and soccer. They tried it for a few years and didn't really enjoy it all that much, so we just kept looking for the next thing. ... in Texas, every recreational sport becomes extremely competitive. It's hard to do anything for fun.

OI-18 stated, "We pull in a lot of the students that might not fit in the stereotypical categories of being a star athlete, or the very athletic, or even active child. We offer an opportunity for all students to participate $100 \%$; nobody sits on the bench". OI-05 elaborated:

Some parents already know if their child is not very athletic and this is a good sport, he's more of an introvert or a self-motivator, they would choose this over another sport. Because the other sport they know that they can't get far because of their coordination or something, their child, but in taekwondo, it's not a team sport where you have to be really good at it to be able to participate, and if you're not good then you'll be sitting on the bench, and some parents are like, "Yeah, he's always on the bench. What good is that for him? That's not building up confidence. We want him to build up his confidence".

Theme 5: Discipline. PI-12 joined specifically because of the discipline and structure. PI-43 said, “....because there's more discipline here. We were looking for [child] not only to defend himself, but also build some self-confidence, and the respect from junior to senior is very, very important. I like that there's someone else reinforcing that behavior..." PI-82 fully expected a structured and disciplined program, stating, "Well I expected that there would be a fair amount of structure and discipline, and I thought that would appeal to my kids". Even in homes where discipline was not an issue, parents valued the discipline taught in classes and reinforcement of parental values. PI-91 explained, "Certainly the discipline, the self-control. Neither one of them has an issue with that, but I liked that being reinforced. That's something that we value at home".

Theme 6: Free trial class. Several parents identified free trial periods as a motivator. According to PI-38, "What [owner] offers here is a free trial week. That was really neat, so you can go in and see if it's going to be a good fit". PI-43 stated a similar opinion:

Having that trial week is a good fit for me. That has sealed the deal for us. If we had to come in and pay a huge amount of money in deposit and buy a uniform just to try it out, that would have been a no-go.

For PI-21, the free trial alleviated thoughts of risk, stating, "I thought, "This would be a good school and they have a month-long trial period." So I figured, "It can't hurt"”.

Theme 7: Affordability. Price was a significant factor. PI-82 said, "It needs to be affordable... I found it to be a little bit more affordable than a lot of other sports per person for the hours that you get". In contrast, PI-29 
compared the cost to daycare, stating, "Honestly, it was the after-school program. The after-school program, and it was a good deal". PI-91 candidly and simply stated, "The cost was a factor".

Theme 8: Media influence. Media influence was identified by both instructors and owners. I-33 shared, "Yeah, media certainly. Even Facebook has just got a host of martial arts stuff on it. Obviously, that's going to influence them". I-66 added, "The Internet helps some, but also just the idea of the old school, like Bruce Lee, and just having their child be able to protect themselves and be individuals". OI-18 stated, "Certainly still with Power Rangers and other martial-arts-inspired shows, that has an impact, especially with younger children". OI-18 went on to elaborate, "We certainly use Facebook a lot to get the word out as opposed to the old-school door-knockers and stuff like that". OI-05 also cited television as an influence: "Yeah, the kids will influence the parents by all the TV shows that they see ..."

Theme 9: Bullying. Bullying is a major social problem with social significant impact. I-33 stated, "Bullying would be number 1". I-66 also explained, “... another incidence was when a child was bullied and they didn't know how to respond to it, so we go through the three Ts. We talk to the bully, we talk to an authoritative person that can do something with it, and we tackle the situation". OI-18 had strong feelings and said, "We definitely hear stories of kids getting bullied and parents wanting their children to learn how to defend themselves better physically, verbally, mentally, emotionally. I think bullying is certainly a pandemic". OI-18 reiterated the following:

Bullying education has really changed over the years. The schools take a different approach to it. Our approach to instructing has changed. We're much more well-rounded. The schools have been approached that they have to have zero tolerance... I think parents appreciate the fact that we are not zero tolerance, that we understand that there is a time and place to defend yourself physically.

OI-05 shared, "They were bullied when they were younger and didn't know how to take charge, and now they have children and their child is being bullied and they want their child to be able to deal with it him- or herself". OI-05 cited tangible examples, "A ton, where kids come in and they have been bullied or they see someone being strong and they can't be strong like that. They get to know that person and realize that it's taekwondo that has made them this way".

Theme 10: Convenience. Convenience was identified an instructor interview. I-33 said the following:

There's also a different side of it, and maybe a darker side of ... cases where parents were not too involved with the children, but they needed a place where children could go straight after work so that they can go and do their errands or shopping or maybe they had their other child already enrolled in an activity or something like that. They needed something convenient at the same time for the other child to do at the same time. They might not have been completely interested, but it was just that convenience.

\subsection{Analysis of Results}

The results of this case study are consistent with consumer behavior research using TPB to predict buyer behavior (Gonzalez et al., 2012; Shareef et al., 2013). The study identified themes describing perceptions aligned with TPB beliefs: (a) normative beliefs, (b) control beliefs, and (c) behavioral beliefs that contribute to intention (Ajzen, 2013; Ajzen \& Klobas, 2013). Study findings validate research exploring adult martial arts participation motivation, specifically physical fitness and self-defense (Cynarski, 2012; Vences de Brito et al., 2015; Witkowski et al., 2013; Zeng et al., 2015).

Ten themes were identified in the study; three new themes emerged from the study: (a) alternative to team sports, (b) ease of participation, and (c) convenience. These new themes are likely due to a combination of the dearth of research focusing on parent martial arts purchase motivation and the difference between an adult making a decision about a leisure activity for themselves versus making a decision about activities for their children. Each theme represents a parental purchase motivation.

Self-defense. Self-defense is supported by the literature and is a potential behavioral and normative belief in the TPB framework referring to the perception of the activity as either good for the individual or viewed as positive by others (Ajzen, 2013; Ajzen \& Klobas, 2013). Self-defense has historically been defined as the ability to protect oneself from harm (Kimm, 2014) and has often been found to be a benefit and motivation for martial arts (Hishinuma, et al., 2012; Vences de Brito et al., 2015; Witkowski et al., 2013). However, parents modified the traditional description for self-defense as a concept that is deeper than physically defending oneself in a conflict. Specifically, parents expressed the benefit of self-defense as "handling one's self during periods of potential altercation". Parents cited skills learned in class such as remaining calm, deescalating situations, having confidence during a crisis, and using an assertive voice to control a situation or seek help. The expanded 
definition of self-defense and the desire of parents for assertive verbal skills and the ability to control a situation, in addition to fighting skills, may be a reflection of trends like zero tolerance in schools and society.

Physical fitness. Physical fitness is supported by the literature and is a potential behavioral and normative belief for the TPB framework (Ajzen, 2013; Ajzen \& Klobas, 2013). Nine study participants expressed physical fitness as a purchase motivator. Physical fitness has long been touted as a benefit of martial arts training and a purchase motivator (Drzał-Grabiec \& Truszczyńska, 2014). Unique benefits identified were cross-training and flexibility to supplement other sports.

Ease of participation. Five of seven parents expressed that the diverse schedule and ease of participating in classes was a strong purchase motivation that enabled juggling between multiple commitments for the child or to deal with activities for multiple children. Several parents also valued the after-school pick-up program. No studies in the literature address this issue. These findings do align with the TPB concept of control beliefs (Ajzen, 2013; Ajzen \& Klobas, 2013) and suggest that the design of the martial arts product offering, the asynchronous nature of classes, individual nondependent attendance, and after-school pick-up programs make attending class an achievable goal with minimal barriers to participation.

Alternative to team sports. Alternative to team sports, mentioned by all three interview groups, does not appear in the literature, and is a potential behavioral and control belief for the TPB framework (Ajzen, 2013; Ajzen \& Klobas, 2013). Reasons for why an alternative to team sports influences parent purchase motivation included the following: (a) child not suited to team sports, (b) negative competitive pressures of team sports, (c) child's refusal to participate in team sports, and (d) child not getting playtime or sitting on the bench during games.

Though this represents a new potential area for buyer motivation in the commercialized martial arts industry, there is a lively discussion on the benefits and negative aspects of organized team sports and competition for youth. Proponents highlight benefits such as developing character, gaining basic social skills, and learning cooperative behaviors; conversely, opponents suggest that team sports undermine character, citing examples of cheating, drug use, and aggressive behaviors (Gaines, 2012; Phillips, 2014).

Discipline. Discipline was identified by the majority of study respondents and is a potential behavioral belief and normative belief for the TPB framework (Ajzen, 2013; Ajzen \& Klobas, 2013). Discipline has long been identified as a benefit of martial arts training (Kimm, 2014; Ko, 2003). Parents appreciated children learning to practice and work hard with their own self-motivation. Instructors stated that the structure of classes promotes discipline, and parents appreciated the reinforcement of positive values in the classroom.

Free trial class. Greater than $50 \%$ of parents expressed value for the free trial offers, which is a potential control belief for the TPB framework (Ajzen, 2013; Ajzen \& Klobas, 2013) and is supported in the literature. The trial lesson encouraged parents to try the school with no upfront costs or commitment, which was a significant incentive and purchase motivation.

Affordability. Cost is a basic component of commerce. There is much discussion in the literature about price and promotions being strong techniques to attract clients (Nelson, 2013; Zou et al., 2014). Parents expressed price, as compared to other activities, being a major factor in motivating them to choose martial arts. Moreover, parents expressed the lower costs and higher value (more contact and participation time) as a key differentiator for martial arts when compared to other activities. This theme supports the TPB framework as a potential control belief (Ajzen, 2013; Ajzen \& Klobas, 2013).

Media influence. All instructors and owners cited media influence as a purchase motivator, while few parents did so. This theme is supported by the literature, which shows that movies have a significant influence in making martial arts appear attainable and exciting (Ding et al., 2015; Nelson, 2013; Vail, 2014). Parents stated that movies and television characters influenced children to want to attain fighting skills. Instructors recognized the influence of older role models such as Bruce Lee and emphasized the positive role of social media in influencing customer attraction. This theme supports the TPB framework as a potential behavioral belief and normative belief (Ajzen, 2013; Ajzen \& Klobas, 2013).

Bullying. Bullying is a widely recognized social problem with dire consequences (Bogart et al., 2014). This theme supports the TPB framework as a potential behavioral belief and normative belief (Ajzen, 2013; Ajzen \& Klobas, 2013). Bullying is prevalent in the literature. Studies have shown that parents do not fully understand the bullying problem and actively seek information to identify and deal with the phenomenon (Harcourt et al., 2014). All instructors and owners expressed that bullying prevention is a purchase motivator, providing examples of bullying scenarios, confidence-building techniques, and specific children with issues. The majority of parents stated bullying prevention as an additional benefit, but did not cite bullying prevention as a motivator to join. 
One parent, though, did enroll their child in class specifically because of a bullying experience.

The differences in strength of opinion here could be role-based. Parents generally spoke of themselves and their individual experiences, whereas instructors and owners had interactions with many parents over time. Instructors may be have been exposed to more victims of bullying and may therefore have given greater significance to bullying as a recurrent social issue.

Convenience. This theme may be related to ease of participation from a parent perspective. However, from the instructor viewpoint it was identified with a negative connotation. The connotation of the theme and the responses of the interview subjects displayed synergy with findings in the literature that martial arts businesses are not always aligned with customer wants and needs. In the past, owners perceived their services less as a commercial product and more of a philosophical knowledge to be shared with those deemed worthy (Hall \& Ryan, 2013; Ko, 2003; Ko \& Kim, 2010; Reese, 2015; Wasik, 2014; Zeng et al., 2015). This point of view arguably has slowed the commercialization of martial arts as a fitness service and a sport.

Convenience was identified strongly by a single instructor and was defined as parents enrolling their children in classes not because of the perceived benefits of taekwondo or martial arts, but rather for the parents' convenience while they performed other activities such as running errands. However, this was expressed in a somewhat negative light, referred to as the "darker side" of motivation. Essentially, the instructor stated that martial arts could be used as an alternate form of daycare and found that to be negative because the parents do not value the benefits of martial arts training or their child's participating in the activity in the proper way. This theme supports the TPB framework as a potential control belief and behavioral belief.

\section{Discussion}

Respondent interviews essentially identified the "voice" of the customer and provided valuable data. The study findings revealed several insights that enable recommendations for practice, theory, and future research. Recommendations for practice center on marketing messages, product offerings, and customer segmentation. Recommendations for theory include using study findings to apply TPB and examining the interactions of core TPB concepts. Recommendations for future research include expanding the study to different geographies and using the qualitative results to seed future quantitative studies

\subsection{Recommendations for Practice}

The first recommendation for practice is for martial arts businesses to consider identifying children who do not enjoy or wish to participate in team sports and to create a specific customer segment for this group. Customer segmentation has proved to be a powerful tool to understand customers (Rao, 2015). This technique allows businesses to identify customer needs, to provide quality service to customers and meet expectations, and to accurately predict future customer needs (Soloman, 2013). Identifying underserved segments allows businesses to engage with new customers and outperform competitors (Amankwah-Amoah, 2014).

Owners should create specific marketing messages tailored to this group outlining the benefits of martial arts training to those who prefer individualized activity and should stress individual participation and non-negative competitive pressures. Sales and closing process should be modified to include these data. Adopting this strategy would potentially help attract new customers and increase sales closure rates.

The second practice recommendation is to continue to emphasize the traditional value messages ofself-defense, physical fitness, and bullying prevention, which are still valid in the minds of consumers. However, the messages surrounding physical fitness, self-defense, and bullying prevention should be refined and expanded to reflect current social trends. Martial arts business owners should consider evaluating their current marketing messages, product offerings, and sales tools regarding physical fitness, self-defense, and bullying prevention and revise them.

Parents find martial arts a valuable part of a continuing fitness program, with a unique benefit of flexibility that is not present in many other fitness activities (Vences de Brito et al., 2015). Researchers have validated that physical fitness is a strong benefit of martial arts training and a good outlet for regular exercise (Drzał-Grabiec \& Truszczyńska, 2014; Vences de Brito et al., 2015). Martial arts firms should stress physical fitness as a benefit of martial arts training and stress flexibility as a unique benefit, a differentiator to help create a competitive advantage over other fitness activities (McKnight et al., 2014; Williams et al., 2012). Employees and instructors tasked with sales responsibilities should be trained to emphasize these points during sales calls and customer interactions.

Similarly, researchers have historically found self-defense to be a martial arts benefit that is desirable to consumers (Hishinuma et al., 2012; Witkowski et al., 2013). However, study findings show that 
parentperceptions of self-defense go beyond physical fighting skills and include items such as (a) the ability to remain calm during conflict, (b) building strong verbal skills, (c) understanding how to escalate to appropriate authority figures, and (d) using restraint when physical force is required. Social trends such as zero tolerance require specific skills during conflict management (Heilbrun et al., 2015; Ward, 2014). Martial arts firms should create marketing messages that emphasize self-defense benefits and the confidence and soft skills mentioned above toenable students to defend themselves and de-escalate conflict appropriately without violence in zero-tolerance environments. Martial arts owners should investigate local school requirements regarding altercations and should create product offerings accordingly.

Bullying is a serious problem with severe consequences to self-esteem, confidence, and development, as well as causing physical harm and even death (Moor \& Merry, 2014). Even though efforts have been made to increase awareness, parents are struggling to (a) identify bullying incidents, (b) understand the cause of bullying, and (c) understand the social factors affecting bullying (Harcourt et al., 2014). Martial arts firms should create marketing messages describing the full range of benefits for bullying prevention that go beyond self-defense skills and include items such as parent/child education, self-defense, verbal de-escalation, and engaging authority figures. Sales training should be created to ensure that sales meetings emphasize the specific value to parents in helping them identify and deal with bullying issues.

The third practice recommendation is to emphasize a flexible schedule of classes and trial promotions. Study findings and research indicate that parents strongly value the asynchronous nature of martial arts attendance requirements and the opportunity to sample martial arts classes prior to committing to enrollment (Nelson, 2013; Zaggelidou et al., 2013; Zou et al., 2014). Difficulties in attending multiple activities and inflexible participation requirements are among the leading causes of preteen children dropping out of extracurricular fitness-based activities (Moreau et al., 2014). Martial arts business owners should use this information to create marketing messages that explain the ease of martial arts participation and ability to try classes with little commitment. Employees with sales responsibilities should be trained to highlight these points in sales interactions to ensure that they are properly communicated to parents.

The fourth practice recommendation is to emphasize the price-based value of martial arts training compared to other fitness activities and sports. Study findings show that parents value the low cost of martial arts training compared to the cost of participating in team sports. Indications are that martial arts classes are cheaper than team sports, with less travel and equipment costs, high levels of participation, and more contact time. Differentiation is required to attract and retain customers and gain competitive advantage in the fitness industry (McKnight et al., 2014; Williams et al., 2012). Accordingly, martial arts firms should use marketing messages that highlight the cost-to-value proposition of martial arts to include contact time, cost of entry and participation, and the large amounts of time that the child will get to spend actually participating in the activity as compared to organized team sports. Collateral and sales tools should be generated that demonstrate lower participation cost of martial arts versus sports activities, as well as increased participation time and contact time with instructors and coaches.

\subsection{Recommendations for Future Research}

The first recommendation for future research is to explore other geographies. This study was conducted at a single martial arts school in central Texas. Comparable studies should be conducted in different cities and regions to examine parent purchase motivation for martial arts lessons. Moreover, cross-national studies should be conducted to explore parents' purchase motivation for martial arts.

The second recommendation is to explore other martial arts disciplines. This study examined a single school that teaches a specific martial art, taekwondo. Taekwondo is one of the most popular martial arts (Kim, Zhang, Jackson et al., 2013); research has shown that participation motivation for taekwondo is similar to other martial arts such as karate (Zeng et al., 2015). However, there are many martial arts disciplines with different characteristics (Kim, Zhang et al., 2009; Kimm, 2014; McNamara, 2008). Future research should include studies in other disciplines to examine the motivations for purchase and participation to see if they differ.

In addition to recommendations for studies to validate the findings of the current study and to broaden demographic and psychographic variables, the findings of this study can be used as a basis to explore quantitative research (Duxbury, 2012; Yin, 2014). Quantitative studies could explore the themes from the findings of this study to better understand their nature of influence on purchase motivation and weigh them to better understand their relative influence on purchase behavior.

The final recommendation for future research is to explore the strength and relative influence for each type of belief identified by TPB. TPB identifies three types of beliefs that combine to form intention: (a) control beliefs, 
(b) subjective beliefs, and (c) normative beliefs (Ajzen, 2013; Ajzen \& Klobas, 2013). Study findings indicate that parents may find control beliefs to be stronger influences than normative or subjective beliefs, which implies that control beliefs may have a disproportionate influence on purchase behavior for children's martial arts lessons. Further, researchers have called for additional research to identify and refine the influence of internal drivers on motivation to expand TPB (Ajzen, 2014; Gonzalez et al., 2012).

\subsection{Conclusions}

Commercialized martial arts business owners and marketers can use the results of this exploratory, single-case study to gain a better understanding of the purchase motivation of parents who place their children in martial arts classes. Key findings in the study align with relevant research in consumer behavior for the commercialized martial arts industry (Kimm, 2014; Nelson, 2013; Vences de Brito et al. 2015), potentially expand the dimensions of some motivators, and may identify new purchase motivators. An interesting finding shows that unique and potentially underserved market segments revolve around children who are not a fit for team sports (Amankwah-Amoah, 2014). This information can be used to create service offeringsfor martial arts businesses that are valuable to the segment and create a differentiator, which has been shown to create a strong competitive advantage in the fitness industry (McKnight et al., 2014; Williams et al., 2012).

Study findings also validate traditional price and value concerns associated with general commerce. Traditionally, trial promotions have been successful tools for attracting customers in the commercialized martial arts industry (Wang et al., 2013; Zaggelidou et al., 2013). The study findings show that trial promotions are a major factor in many parents' selection of martial arts as an activity for their child, as they allow them to experience the service and better understand the value propositions for lessons. Study findings indicate that parents perceive a strong cost-benefit ratio when compared to team-based sports due to increased contact time and more hours of active participation for children.

One of the most interesting findings of the study is that control beliefs appear to be the strongest of the threeTPB motivators for parent purchase motivation. Study findings indicate that the flexibility of asynchronous participation, combined with the opportunity for individual achievement and nondependence on other players, is a strong purchase motivation. The flexible nature of martial arts classes and ease of attendance may provide an alternative to team sports as a fitness activity, which could potentially overcome a major factor in children under 13 dropping out of fitness activities - difficulty in attending multiple activities and providing activity for multiple children (Moreau et al., 2014).

\section{Acknowledgments}

I would like to thank Dr. Scott Hipsher for his mentoring on qualitative methods and Allison Humphries for her assistance in manuscript copy editing.

\section{References}

Ajzen, I. (2006). TPB Model. Retrieved from http://people.umass.edu/aizen/tpb.diag.html

Ajzen, I. (2013). Constructing a theory of planned behavior questionnaire. Retrieved from http://people.umass.edu/aizen/tpb.html

Ajzen, I. (2014). The theory of planned behaviour is alive and well, and not ready to retire: A commentary on Sniehotta, Presseau, \& Araújo-Soares. Health Psychology Review, 9, 131-137. https://doi.org/10.1080/17437199.2014.883474

Ajzen, I., \& Klobas, J. (2013). Fertility intentions: An approach based on the theory of planned behavior. Demographic Research, 29(8), 203-232.

Ajzen, I., \& Sheikh, S. (2013). Action versus inaction: Anticipated affect in the theory of planned behavior. Journal of Applied Social Psychology, 43, 155-162. https://doi.org/10.1111/j.1559-1816.2012.00989.x

Al-Fattal, A., \& Ayoubi, R. M. (2012). Understanding consumer buyer behaviour in the EFL market: A case-study of a leader provider in Syria. Education, Business, and Society: Contemporary Middle Eastern Issues, 5(4), 237-253. https://doi.org/10.1108/17537981211284425

Amankwah-Amoah, J. (2014). Organizational expansion to underserved markets: Insights from African firms. Thunderbird International Business Review, 56(4), 317-330. https://doi.org/10.1002/tie.21630

Asay, T. M. (2009). The shimmering scales of the dragon: Bruce Lee's cinematic surfaces. Critical Studies in Media Communication, 26(4), 312-330. https://doi.org/10.1080/15295030903176633

Ball, K., \& Martin, J. (2012). Self-defense training and traditional martial arts: Influences of self-efficacy and 
fear related to sexual victimization. Sport Exercise, and Performance Psychology, 1(2), 135-144. https://doi.org/10.1037/a0025745

Barbopoulos, I., \& Johansson, L. O. (2016). A multi-dimensional approach to consumer motivation: Exploring economic, hedonic, and normative consumption goals. Journal of Consumer Marketing, 33(1), 75-84. https://doi.org/10.1108/JCM-08-2014-1091

Baruk, A. I., \& Iwanicka, A. (2016). The effect of age, gender and level of education on the consumer's expectations towards dairy product packaging. British Food Journal, 118(1), 100-118. https://doi.org/10.1108/BFJ-07-2015-0248

Baxter, P., \& Jack, S. (2008). Qualitative case study methodology: Study design and implementation for novice researchers. The Qualitative Report, 13(4), 544-559. Retrieved from http://nsuworks.nova.edu/tqr_home/

Bjerke, R., \& Ind, N. (2015). The influence of aesthetic investments on employees: An investigation of arts' impact on employees. EuroMed Journal of Business, 10(2), 214-233. https://doi.org/10.1108/EMJB-09-2014-0029

Bekhet, A. K., \& Zauszniewski, J. A. (2012). Methodological triangulation: an approach to understanding data. Nurse Researcher, 20(2), 40-43. https://doi.org/10.7748/nr2012.11.20.2.40.c9442

Choi, H. H. (1965). Taekwondo: The Art of Self-defense (1st ed.). Seoul, Korea: Daeha.

Cronin, C. (2014). Using case study research as a rigorous form of inquiry. Nurse Researcher, 21(5), 19-27. https://doi.org/10.7748/nr.21.5.19.e1240

Cynarski, W. J. (2012). Values of martial arts in the light of the anthropology of martial arts. Journal of Combat Sports and Martial Arts, 3, 1-4. https://doi.org/10.5604/20815735.1047608

Cynarski, W. J. (2013). Social stratification in Japanese and some other martial arts: A comparison and discussion of changes. Physical Culture and Sport, 59(1), 49-59. https://doi.org/10.2478/pcssr-2013-0024

Dasgupta, M. (2015). Exploring the relevance of case study research. Vision: The Journal of Business, 19(2), 147-160. https://doi.org/10.1177/0972262915575661

Drzał-Grabiec, J., \& Truszczyńska, A. (2014). Evaluation of selected postural parameters in children who practice kyokushin karate. Biomedical Human Kinetics, 6(1), 69-73. https://doi.org/10.2478/bhk-2014-0013

Duxbury, T. (2012). Towards more case study research in entrepreneurship. Technology Innovation Management Review, 2(3), 9-17. Retrieved from http://www.timereview.ca

Fishbein, M., \& Ajzen, I. (1975). Belief, Attitude, Intention, and Behavior: An Introduction to Theory and Research. Reading, MA: Addison-Wesley.

Friman, H. R. (1998). The art of regulation: Martial arts as threats to social order. Journal of Asian Martial Arts, 7(3), 11-23. Retrieved from http://www.journalofasianmartialarts.com

Gaines, S. A. (2012). Theory into practice: Developing individual and team character in sport. Strategies, 25(8), 30-33. https://doi.org/10.1080/08924562.2012.10592180

Gonzalez, S. T., Lopez, M. C. N., Marcos, Y. Q., \& Rodriguez-Marin, J. (2012). Development and validation of the theory of planned behavior questionnaire in physical activity. The Spanish Journal of Psychology, 15(2), 801-816. https://doi.org/10.5209/rev_SJOP.2012.v15.n2.38892

Green, D. (2011). The demographics of MMA: Know the combat sport industry. Retrieved from http://www.examiner.com/article/the-demographics-of-mma-know-the-combat-sport-industry

Green, T., \& Svinth, J. (2003). Martial Arts in the Modern World. Westport, CT: Praeger.

Greenwell, T. C., Hancock, M., Simmons, J. M., \& Thorn, D. (2015). The effects of gender and social roles on the marketing of combat sport. Sport Marketing Quarterly, 24(1), 19-29. Retrieved from http://fitpublishing.com/journals/smq

Hall, T., \& Ryan, T. (2013). Media consumption of mixed martial arts among college students: A preliminary examination. Journal of Contemporary Athletics, 7(2), 87-101. Retrieved from https://www.novapublishers.com/catalog/product_info.php?cPath=125\&products_id=1673

Harcourt, S., Jasperse, M., \& Green, V. A. (2014). "We were sad and we were angry": A systematic review of parents' perspectives on bullying. Child \& Youth Care Forum, 43(3), 373-391. https://doi.org/10.1007/s10566-014-9243-4 
Head, K. J., \& Noar, S. M. (2014). Facilitating progress in health behaviour theory development and modification: The reasoned action approach as a case-study. Health Psychology Review, 8, 35-52. https://doi.org/10.1080/17437199.2013.778165

Heilbrun, A., Cornell, D., \& Lovegrove, P. (2015). Principal attitudes regarding zero tolerance and racial disparities in school suspensions. Psychology in the Schools, 52(5), 489-499. https://doi.org/10.1002/pits.21838

Hishinuma, E. S., Umemoto, K. N., Nguyen, T. G., Chang, J. Y., \& Bautista, R. P. M. (2012). Epidemiology of mixed martial arts and youth violence in an ethnically diverse sample. Violence and Victims, 27(1), 43-69. https://doi.org/10.1891/0886-6708.27.1.43

Houghton, C., Casey, D., Shaw, D., \& Murphy, K. (2013). Rigour in qualitative case-study research. Nurse Researcher, 20(4), 12-17. https://doi.org/10.7748/nr2013.03.20.4.12.e326

InfoUSA. (2015). Business mailing lists and sales leads. Retrieved from http://leads.infousa.com/Business/ReviewCriteria.aspx

John, D. R., \& Park, J. K. (2016). Mindset matter: Implications for branding research and practice. Journal of Consumer Psychology, 26(1), 153-160. https://doi.org/10.1016/j.jcps.2015.06.010

Jones, G. W., Mackay, K. S., \& Peters, D. M. (2006). Participation motivation in martial arts in the West Midlands region of England. Journal of Sports Science and Medicine, 5(CSSI), 28-34. Retrieved from http://www.jssm.org

Kim, J., Heo, J., King, C., \& Kim, S. (2014). Cultural understanding and personal growth through Taekwondo as a cross-cultural activity. Journal of Humanistic Psychology, 54(3), 356-376. https://doi.org/10.1177/0022167813504826

Kim, M. K., Zhang, J., Jackson, E. N., Connaughton, D. P., \& Kim, M. (2013). Modification and revision of scale of market demand for Taekwondo schools. Measurement in Physical Education and Exercise Science, 17, 187-207. https://doi.org/10.1080/1091367X.2013.805136

Kim, M. K., Zhang, J. J., \& Ko, Y. J. (2009). Dimensions of market demand associated with Taekwondo schools in North America: Development of a scale. Sports Management Review, 12, 149-166. https://doi.org/10.1016/j.smr.2009.01.003

Kim, Y., \& Park, H. (2013). Does regular exercise without weight loss reduce insulin resistance in children and adolescents? International Journal of Endocrinology, 2, 1-10. https://doi.org/10.1155/2013/402592

Kim, Y. J., Nijite, D., \& Hancer, M. (2013). Anticipated emotion in consumers' intentions to select eco-friendly restaurants: Augmenting the theory of planned behavior. International Journal of Hospitality Management, 34, 255-262. https://doi.org/10.1016/j.ijhm.2013.04.004

Kimm, H. (2014). Taekwondo History. Baton Rouge, LA: Hando Press.

Klöckner, C. A. (2013). A comprehensive model of the psychology of environmental behaviour-A $\begin{array}{llll}\text { meta-analysis. } & \text { Global } & \text { Environmental } & \text { Change, }\end{array}$ https://doi.org/10.1016/j.gloenvcha.2013.05.014

Ko, Y. J. (2003). Martial arts marketing: Putting the customer first. Journal of Asian Marital Arts, 12(2), 9-15. Retrieved from www.journalofasianmartialarts.com

Ko, Y. J., \& Kim, Y. K. (2010). Martial arts participation: Consumer motivation. International Journal of Sports Marketing \& Sponsorship, 11(2), 105-123. https://doi.org/10.1108/IJSMS-11-02-2010-B002

Ko, Y. J., \& Yang, J. B. (2012). The globalization of martial arts: The change of rules for new markets. Journal of Asian Martial Arts, 4(1), 8-19.

Koenig-Lewis, N., \& Palmer, A. (2008). Experiential value over time-a comparison of measures of satisfaction and emotion. Journal of Marketing Management, 24(1-2), 69-85. https://doi.org/10.1362/026725708X273920

Kotler, P., \& Keller, K. L. (2015). Marketing Management (15th ed.). Upper Saddle River, NJ: Prentice Hall.

Leedy, P. D., \& Ormond, J. E. (2015). Practical Research: Planning and Design (11th ed.). Boston, MA: Pearson.

Lincoln, Y. S., \& Guba, E. G. (1985). Naturalistic Inquiry. Newbury Park, CA: Sage. 
Locke, B. (2014). "The white man's Bruce Lee": Race and the construction of white masculinity in David Fincher's Fight Club 1989. Journal of Asian American Culture, 17(1), 61-89. https://doi.org/10.1353/jaas.2014.0009

Marshall, B., Cardon, P., Poddar, A., \& Fontenot, R. (2013). Does sample size matter in qualitative research? A review of qualitative interviews in IS research. Journal of Computer Information Systems, 54(1), 11-22. https://doi.org/10.1080/08874417.2013.11645667

McKnight, O. T., Paugh, R., McKnight, J., Zuccaro, L., \& Tornabene, G. (2014). Marketing athletic clubs, recreation centers and country clubs: Recruiting and retaining members using psychodemographics. American Journal of Management, 14(4), 60-67. Retrieved from https://works.bepress.com/oscar_mcknight/52/

McNamara, J. D. (2008). The effect of modern marketing on martial arts and traditional martial arts culture. Sport Journal, 10(1), 5-9. Retrieved from http://thesportjournal.org/

Mertens, D. M., \& Hesse-Biber, S. (2012). Triangulation and mixed methods research: Provocative positions. Journal of Mixed Methods Research, 6, 75-79. https://doi.org/10.1177/1558689812437100

Miller, M. (2008). Ultimate cash machine. Forbes. Retrieved from www.forbes.com/forbes/2008/0505/080.html

Moor, S., \& Merry, S. N. (2014). Depression and bullying in children. The New Zealand Medical Journal (Online), 127(1390), 6-9. Retrieved from http://journal.nzma.org.nz

Moreau, N., Chanteau, O., Benoît, M., Dumas, M.-p., Laurin-lamothe, A., Parlavecchio, L., \& Lester, C. (2014). Sports activities in a psychosocial perspective: Preliminary analysis of adolescent participation in sports challenges. International Review for the Sociology of Sport, 49(1), 85-101. https://doi.org/10.1177/1012690212452361

Mullin, B., Hardy, S., \& Sutton, W. (2013). Sport Marketing (4th ed.). Champaign, IL: Human Kinetics.

Murphy, M. C., \& Dweck, C. S. (2016). Mindsets shape consumer behavior. Journal of Consumer Psychology, 26(1), 127-136. https://doi.org/10.1016/j.jcps.2015.06.005

Naraine, M. L., \& Dixon, J. C. (2013). "Frame-changing" the game: Examining the media framing of mixed martial arts discourse in Ontario. Communication \& Sport, 2(2), 186-199. https://doi.org/10.1177/2167479513479349

Nelson, C. A. (2013). Services marketing in mixed martial arts, development Jiu Jitsu in Seoul, Korea. Journal of Marketing and Management, 4(1), 31-45. Retrieved from http://www.gsmi-ijgb.com/Pages/JMM.aspx

Petra, M. (2012). Research of the behavior of consumers in the insurance market in the Czech Republic. Journal of Competitiveness, 4(2), 20-37. https://doi.org/10.7441/joc.2012.02.02

Phillips, B. P. (2014). Clear eyes, full hearts, can lose: Fridy Nigh Lights and the myth of the rewarding of morality in sports. Journal of Popular Culture, 47(5), 990-1004. https://doi.org/10.1111/jpcu.12184

Powell, S., Langlands, S., \& Dodd, C. (2011). Feeding children's desires?: Child and parental percptions of food promotion to "under 8s". Young Consumers: Insight and Ideas for Responsible Marketers, 12(2), 96-109. https://doi.org/10.1108/17473611111141560

Rao, M. (2015). Market segmentation. Golden Research Thoughts, 4(7), 1-3. Retrieved from http://aygrt.irj.org

Reese, J. (2015). Rugged and exciting: Examining the personality of a mixed martial arts brand. Journal of Contemporary Athletics, $\quad 9(2), \quad 101-115 . \quad$ Retrieved from https://www.novapublishers.com/catalog/product_info.php?cPath=125\&products_id=1673

Robinson, O. C. (2014). Sampling in interview-based qualitative research: A theoretical and practical guide. Qualitative Research in Psychology, 11(1), 25-41. https://doi.org/10.1080/14780887.2013.801543

Rubin, H. J., \& Rubin, I. S. (2012). Qualitative Interviewing: The Art of Hearing Data (3rd ed.). Thousand Oaks, CA: Sage Publications.

Sargeant, J. (2012). Qualitative research part II: Participants, analysis, and quality assurance. Journal of Graduate Medical Education, 4, 1-3. https://doi.org/10.4300/JGME-D-11-00307.1

Shareef, M. A., Kumar, V., Kumar, U., \& Hasin, A. A. (2013). Application of behavior theory in predicting consumer's adoption behavior. Journal of Information Technology Research, 6(4), 36-54. https://doi.org/10.4018/jitr.2013100103 
Sharma, S., \& Kashmiri, L. (2012). Changing consumer behaviour-A challenge for sustainable business growth. International Journal of Marketing, Financial Services \& Management Research, 1(8), 149-158. Retrieved from http://www.indianresearchjournals.com

Sobh, R., \& Martin, B. A. S. (2012). Feedback information and consumer motivation: the moderating role of positive and negative reference values in self-regulation. European Journal of Marketing, 45(6), 963-986. https://doi.org/10.1108/03090561111119976

Soloman, M. R. (2013). Consumer Behavior (10th ed.). Boston, MA: Pearson.

Taghavi, M., \& Seyedsalehi, A. (2015). The effect of packaging and brand on children's and parents' purchase decisions and the moderate role of pester power. British Food Journal, 117(8), 2017-2038. https://doi.org/10.1108/BFJ-07-2014-0260

Theeboom, M., Deknop, P., \& Vertonghen, J. (2009). Experience of children in martial arts. European Journal for Sport and Society, 6(1), 19-35.

Twemlow, S. W., Biggs, B. K., Nelson, T. D., Vernberg, E. M., Fonagy, P., \& Twemlow, S. W. (2008). Effects of participation in martial arts-based anti-bullying program in elementary schools. Psychology in the Schools, 45, 947-959. https://doi.org/10.1002/pits.20344

U.S. Department of Commerce, United States Census Bureau. (2015). Vintage 2005: National Tables. Retrieved from http://www.census.gov/popest/data/historical/2000s/vintage_2005/index.html

Vail, P. (2014). Muay Thai: Inventing tradition for a national symbol. SOJOURN: Journal of Social Issues in Southeast Asia, 29(3), 509-553. https://doi.org/10.1355/sj29-3a

Vences de Brito, A. M., Ferreira Rodrigues, M. A. F., Cynarski, W. J., \& Guiterrez García, C. G. (2015). Aging effects on neuromuscular activity in karate practitioners. Journal of Sports Science, 3(5), 203-213.

Vertonghen, J., \& Theeboom, M. (2013). How to obtain more insight into the true nature of outcomes of youth martial arts practice? Journal of Children's Services, 8(4), 244-253. https://doi.org/10.1108/JCS-03-2013-0006

Vinerean, S., Cetina, I., Dumitrescu, L., \& Tichindelean, M. (2013). The effects of social media marketing on online consumer behavior. International Journal of Business and Management, 8(14), 66-79. https://doi.org/10.5539/ijbm.v8n14p66

Wang, Y., Ma, S., \& Li, D. (2015). Customer participation in virtual brand communities: The self-construal perspective. Information \& Management, 52(5), 577-587. https://doi.org/10.1016/j.im.2015.04.003

Wang, T., Oh, L. B., Wang, K., \& Yuan, Y. (2013). User adoption and purchasing intention after free trial: An empirical study of mobile newspapers. Information Systems and eBusiness Management, 11, 189-210. https://doi.org/10.1007/s10257-012-0197-5

Wasik, J. (2014). Three areas of Taekwondo identification and practice. Journal of Martial Arts Anthropology, 14, 22-26.

Webb, T. L., \& Sheeran, P. (2006). Does changing behavioral intentions engender behavior change? A meta-analysis of the experimental evidence. Psychological Bulletin, 132(2), 249-268. https://doi.org/10.1037/0033-2909.132.2.249

Wells, J. J. (2015). Youth mixed martial arts: Time to regulate. Clinical Pediatrics, 54(3), 282. https://doi.org/10.1177/0009922814540041

White, K., Argo, J. J., \& Sengupta, J. (2012). Dissociative versus associative responses to social identity threat: The role of consumer self-construal. Journal of Consumer Research, 39(4), 704-719. https://doi.org/10.1086/664977

Williams, W. S., Pedersen, P. M., \& Walsh, P. (2012). Brand association in the fitness segment of the sports industry in the United States: extending spectator sports branding conceptualizations and dimensions to participatory sports. International Journal of Sports Marketing and Sponsorship, 14(1), 29-45. https://doi.org/10.1108/IJSMS-14-01-2012-B004

Witkowski, K., Cynarski, W., \& Blazejewski, W. (2013). Motivation and determinants underlying the practice of martial arts and combat sports. Ido-Movement for Culture: Journal of Martial Arts Anthropology, 13(1), $17-26$.

Yang, H., Stamatogiannakis, A., \& Chattopadhyay, A. (2015). Pursuing attainment versus maintenance goals: 
The interplay of self-construal and goal type on motivation. The Journal of Consumer Research, 42(1), 93-108. https://doi.org/10.1093/jcr/ucv008

Yin, R. K. (2014). Case-study Research: Design and Methods (5th ed.). London, United Kingdom: Sage.

Zaggelidou, E., Tsamourtzis, E., Malkogeorgos, A., \& Zaggelidis, G. (2013). The effect of marketing on dance activity. Journal of Physical Education and Sport, 13(2), 220-230.

Zeng, H. Z., Cynarski, W. J., Baatz, S., \& Park, S. J. (2015). Exploring motivations of taekwondo athletes/students in New York City. World Journal of Education, 5(5). https://doi.org/10.5430/wje.v5n5p51

Zetaruk, M. N., Violan, M. A., Zurakowski, D., \& Micheli, L. J. (2005). Injuries in martial arts: A comparison of five styles. British Journal of Medicine, 39(1), 29-33.

Zou, L., Zhang, L., \& Ouyang, L. (2014). Membership preference among Chinese martial arts participants. Research Quarterly for Exercise and Sport, 85(S1), A127.

\section{Copyrights}

Copyright for this articleis retained by the author(s), with first publication rights granted to the journal.

This is an open-access article distributed under the terms and conditions of the Creative Commons Attribution license (http://creativecommons.org/licenses/by/4.0/). 